OPEN ACCESS

Edited by:

David Berry,

University of Vienna, Austria

Reviewed by:

Borja Sanchez,

Instituto de Productos Lácteos

de Asturias - Consejo Superior de Investigaciones Científicas, Spain

Chiara Ferrario,

University of Parma, Italy

*Correspondence:

David A. Sela

davidsela@umass.edu

Specialty section:

This article was submitted to

Microbial Symbioses,

a section of the journal

Frontiers in Microbiology

Received: 26 February 2016

Accepted: 27 March 2016

Published: 19 April 2016

Citation:

Yeung TW, Üçok EF, Tiani KA, McClements DJ and Sela DA (2016)

Microencapsulation in Alginate and Chitosan Microgels to Enhance Viability of Bifidobacterium longum for Oral Delivery.

Front. Microbiol. 7:494.

doi: 10.3389/fmicb.2016.00494

\section{Microencapsulation in Alginate and Chitosan Microgels to Enhance Viability of Bifidobacterium longum for Oral Delivery}

\author{
Timothy W. Yeung ${ }^{1}$, Elif F. Üçok ${ }^{1}$, Kendra A. Tiani ${ }^{1,2}$, David J. McClements ${ }^{1,3}$ and \\ David A. Sela ${ }^{1,3,4 *}$
}

${ }^{1}$ Department of Food Science, University of Massachusetts, Amherst, MA, USA, ${ }^{2}$ Commonwealth Honors College, University of Massachusetts, Amherst, MA, USA, ${ }^{3}$ Center for Bioactive Delivery, Institute of Applied Life Science, University of Massachusetts, Amherst, MA, USA, ${ }^{4}$ Center for Microbiome Research, University of Massachusetts Medical School, Worcester, MA, USA

Probiotic microorganisms are incorporated into a wide variety of foods, supplements, and pharmaceuticals to promote human health and wellness. However, maintaining bacterial cell viability during storage and gastrointestinal transit remains a challenge. Encapsulation of bifidobacteria within food-grade hydrogel particles potentially mitigates their sensitivity to environmental stresses. In this study, Bifidobacterium longum subspecies and strains were encapsulated in core-shell microgels consisting of an alginate core and a microgel shell. Encapsulated obligate anaerobes Bifidobacterium longum subsp. infantis and Bifidobacterium longum subsp. longum exhibited differences in viability in a strain-dependent manner, without a discernable relationship to subspecies lineage. This includes viability under aerobic storage conditions and modeled gastrointestinal tract conditions. Coating alginate microgels with chitosan did not improve viability compared to cells encapsulated in alginate microgels alone, suggesting that modifying the surface charge alone does not enhance delivery. Thus hydrogel beads have great potential for improving the stability and efficacy of bifidobacterial probiotics in various nutritional interventions.

Keywords: microencapsulation, bifidobacteria, probiotics, simulated digestion, oral delivery

\section{INTRODUCTION}

Beneficial bacteria are often incorporated into functional foods and nutritional interventions to be ingested orally as probiotics. This includes humans and livestock animals that receive direct-fed microbials to enhance health outcomes and reduce pathogen load (Braat et al., 2006; Puccio et al., 2007; Neal-McKinney et al., 2012; Watson and Preedy, 2015). Bifidobacterium longum colonizes the human gastrointestinal tract (GIT) and is one of the 48 recognized taxa that are encompassed within the genus Bifidobacterium (Milani et al., 2014; Sun et al., 2015). This obligate anaerobe is one of the earliest colonizers of the infant GIT, and is present in lower concentrations in the adult gut (Schell et al., 2002; Sela et al., 2008). The bifidobacterial taxa longum, infantis, and suis were previously classified as discrete species, but more recently they were reclassified as subspecies of B. longum (Sakata et al., 2002). Their unification as a single species is based primarily on genomic 
and phenotypic similarities shared between these groups. While Bifidobacterium animalis subsp. lactis is often used for probiotic applications, B. longum strains are of particular interest due to its likely co-evolution with humans. This is evident in B. longum utilization of human milk oligosaccharides and establishes a protective gut microbiome in infants through adulthood (Sela and Mills, 2010).

Bifidobacterium longum is deployed in several probiotic applications using a variety of delivery formats (Adhikari et al., 2000; Fortin et al., 2011; Amine et al., 2014; Lewis et al., 2015). A relatively large dose of probiotics is recommended to impart health benefits, typically $10^{6}-10^{7} \mathrm{CFU} / \mathrm{g}$ per day (Krasaekoopt et al., 2003; Roy, 2005). However, the direct incorporation of free probiotic cells into food products and supplements results in a significant decrease in cell viability throughout storage and gastrointestinal transit (Sultana et al., 2000; de Vos et al., 2010). Therefore, prolonged storage and the process of ingesting these probiotics may reduce their viability below recommended levels to achieve health benefits. Microencapsulating probiotic cells within hydrogel matrices protects them against extrinsic environmental factors thereby enhancing bacterial survival during processing, storage, and digestion (de Vos et al., 2010; Fareez et al., 2015; Yeung et al., 2016). Encapsulation may also dictate the controlled release of the probiotic at the precise anatomical site of activity within the GIT, thereby enhancing the efficacy of the probiotic through specific targeting after oral delivery (de Barros et al., 2015; Zhang et al., 2015b).

Several biopolymer materials are available to encapsulate microbes in hydrogel matrices, depending on the desired physicochemical properties of the delivery vehicle. The most commonly used food-grade biopolymers are proteins (e.g., whey proteins and caseins) and carbohydrates (e.g., starch and gums; Bagchi et al., 2010; Gaonkar et al., 2014; Etchepare et al., 2015). For many food applications, it is advantageous to encapsulate probiotics within hydrogel beads that trap bacteria within small particles containing cross-linked biopolymer molecules. These microgels must be engineered to encapsulate high concentrations of probiotics and protect them from environmental stresses, such as acidic $\mathrm{pH}$, bile salts, and digestive enzymes (Zhang et al., 2015a). Alginate has been widely used as a biopolymer suitable for food applications as it is relatively inexpensive, easy to gel, biodegradable, and compatible with many food systems (Gombotz and Wee, 2012; Lee and Mooney, 2012). Indeed, recently studies have shown that lactococcal-based probiotics can be encapsulated within alginate microgels to improve their stability (Yeung et al., 2016).

There are appreciable differences between probiotic strain tolerance toward environmental and gastrointestinal stresses. Consequently, it is possible to identify particular strains that are more resistant to these stresses than others, which are therefore more suitable for commercial application (Godward et al., 2000; Krasaekoopt et al., 2004; Capela et al., 2006). As an anaerobe, bifidobacterial species including $B$. longum differ in their sensitivity to oxygen exposure and other environmental stresses during the preparative phase prior to probiotic deployment (Kawasaki et al., 2006; Ruiz et al., 2012). Therefore, bifidobacterial probiotics may be encapsulated to restrict oxidative damage during preparation and storage and to limit exposure to degradative processes within the GIT.

The aim of this study was to design, fabricate, and characterize a food-grade encapsulation system to protect B. longum cells during simulated storage and gastrointestinal passage. Previously, we demonstrated that encapsulation of probiotics within alginate microgels could improve their viability during storage (Yeung et al., 2016). In the current study, we encapsulated B. longum cells within alginate beads to determine if their viability could be enhanced in storage and gastrointestinal transit. Moreover, the impact of coating these alginate beads with a layer of chitosan was investigated as well. Chitosan coated alginate beads have previously been used to enhance the mucoadhesive properties of probiotic bacteria (Chen et al., 2013).

\section{MATERIALS AND METHODS}

\section{Preparation of Bacterial Cultures}

Four strains of both Bifidobacterium longum subsp. longum (B. longum) and Bifidobacterium longum subsp. infantis (B. infantis) were studied (Table 1). All strains were originally isolated from infant feces. Stock solutions were maintained by storing bacteria at $-80^{\circ} \mathrm{C}$ in deMann, Regosa, Sharpe (MRS) media with $0.05 \%$ L-cysteine in $25 \%$ glycerol. Bacteria were propagated in MRS with L-cysteine at $37^{\circ} \mathrm{C}$ for $24 \mathrm{~h}$, checked for purity, and maintained on MRS agar anaerobically. Anaerobic conditions were maintained in a double chamber anaerobic hood with an airlock $\left(88 \% \mathrm{~N}_{2}, 10 \% \mathrm{CO}_{2}\right.$, and $\left.2 \% \mathrm{H}_{2}\right)$ from Coy Laboratory Products (Grass Lake, Mississippi, USA).

Isolated colonies were routinely propagated in MRS broth $(50 \mathrm{~mL})$ for $40 \mathrm{~h}$ at $37^{\circ} \mathrm{C}$. Cells were harvested by centrifugation at $4000 \times g$ for $10 \mathrm{~min}$, washed twice with $0.85 \% \mathrm{NaCl}$ (physiological saline) solution $(25 \mathrm{~mL})$, and suspended in $0.85 \% \mathrm{NaCl}(2 \mathrm{~mL})$. The resulting cell suspensions were used either directly for assessing survival of free cells (i.e., no encapsulation) or subjected to encapsulation as described in section "Microencapsulation of Bifidobacterial Cells." Free cell suspensions $(2 \mathrm{~mL})$ were stored in $0.85 \% \mathrm{NaCl}$ solution $(50 \mathrm{~mL})$ at $2-5^{\circ} \mathrm{C}$ for up to 5 weeks to model long-term storage conditions.

\section{TABLE 1 | Bifidobacterium longum strains selected for encapsulation.}

\begin{tabular}{lc}
\hline Subspecies & Strain designation \\
\hline infantis & UMA 298 \\
& UMA 299 \\
UMA 300 \\
UMA 305 \\
Ungum \\
UMA 306 \\
UMA 318 \\
UMA 401 \\
UMA 402
\end{tabular}




\section{General Chemicals Used in Encapsulation and Modeled Digestion}

For bacterial culture preparation, MRS broth was obtained from Becton Dickinson and Company (Sparks, MD, USA). Agar, L-cysteine hydrochloric acid, and sodium chloride $(\mathrm{NaCl})$ were purchased from Sigma-Aldrich (St. Louis, MO, USA). Glycerol and sodium citrate dihydrate was purchased from Fisher Scientific (Fair Lawn, NJ, USA).

For encapsulation experiments, sodium alginate (TICA-algin HG 400 powder) was donated by TIC Gums (White Marsh, ML, USA). Calcium chloride hexahydrate, chitosan (medium molecular weight) was obtained from Sigma-Aldrich. Glacial acetic acid was purchased from Fisher Scientific.

For simulated digestion, ammonium nitrate, bile extract porcine, lipase from porcine pancreas type II, pepsin from porcine gastric mucosa, porcine gastric mucin type II, potassium chloride, potassium citrate, potassium phosphate, sodium DLlactate, sodium hydroxide $(\mathrm{NaOH})$, and uric acid sodium salt were also purchased from Sigma-Aldrich. Hydrochloric acid $(\mathrm{HCl})$, phosphate buffer saline (PBS), and urea were purchased from Fisher Scientific.

\section{Microencapsulation of Bifidobacterial Cells}

Bifidobacteria were encapsulated within alginate microgels using an injection-gelation method (Whelehan and Marison, 2011; Seiffert, 2013). Briefly, $1 \%(\mathrm{w} / \mathrm{v})$ sodium alginate solution was prepared, autoclaved, and then cooled to ambient temperature. The sterile alginate solution $(198 \mathrm{~mL})$ was mixed with $2 \mathrm{~mL}$ of $\sim 10^{9} \mathrm{CFU} / \mathrm{mL}$ probiotic organisms suspended in physiological saline. The polymeric solution was agitated to uniformly distribute cells throughout the mixture. The alginate beads were prepared aseptically using an encapsulator (Büchi B- $390^{\circledR}$, Büchi Labortechnik AG, Flawil, Switzerland) with a nozzle size of $120 \mu \mathrm{m}$, using the manufacturer's standard operating conditions (amplitude 3, frequency $800 \mathrm{~Hz}$, electrode $800 \mathrm{~V}$, pressure 250$300 \mathrm{mbar}$ ). Aliquots of probiotic/alginate solution were injected into $0.1 \mathrm{M}$ calcium chloride solution $(350 \mathrm{~mL})$. After 1 -h gelation under agitation, the resulting calcium alginate beads were collected by filtration, rinsed with sterile deionized water $(200 \mathrm{~mL})$, and re-filtered. Microbeads $(\sim 30 \mathrm{~mL})$ were stored in physiological saline solution $(50 \mathrm{~mL})$ at $4^{\circ} \mathrm{C}$ for up to 4 weeks to model long-term storage conditions. This process was repeated for all eight strains of bifidobacteria.

Unfilled alginate beads were prepared identically but without the addition of bacterial strains to the alginate solution. $1 \%$ alginate solution $(200 \mathrm{~mL})$ was extruded into of $0.1 \mathrm{M} \mathrm{CaCl}_{2}$ $(350 \mathrm{~mL})$ solution under continuous agitation. The working parameters (nozzle diameter, frequency, charge, and pressure), filtering steps and storage conditions used were the same as those for the preparation of filled alginate beads.

An aqueous chitosan solution $(0.4 \% \mathrm{w} / \mathrm{v})$ was prepared as described previously by Zhou et al. (1998). Briefly, chitosan $(0.4 \mathrm{~g})$ was dissolved in distilled water $(90 \mathrm{~mL})$ and glacial acetic acid $(0.8 \mathrm{~mL})$. The $\mathrm{pH}$ was adjusted to $5.0-5.1$ with $\mathrm{NaOH}$, and the total volume was adjusted to $100 \mathrm{~mL}$. The solution was autoclaved and filtered to remove undissolved solids. Subsequently, the alginate beads were submerged in the chitosan solution to provide a secondary coating by electrostatic attraction of the cationic chitosan molecules to the surfaces of the anionic alginate beads. The mixture was agitated for $1 \mathrm{~h}$ before filtering and rinsing beads with sterile distilled water. Chitosancoated alginate beads were then stored and analyzed as described in section "Alginate and Chitosan-coated Alginate Microbead Characterization."

\section{Alginate and Chitosan-Coated Alginate Microbead Characterization \\ Particle Size Distribution}

The particle size distribution was determined by static light scattering (Mastersizer S, Malvern Instruments, Worcestershire, UK). Each sample (1-2 mL) was suspended in distilled water $(10 \mathrm{~mL})$ and vortexed to avoid multiple scattering effects and to ensure homogeneity prior to analysis. Volume-weighted (D $[4,3]$ ) and surface-weighted (D [3,2]) mean particle diameters were obtained for all samples.

\section{Optical Microscopy Characterization}

The overall appearance of alginate and chitosan-coated alginate beads was characterized with an optical microscope (C1 Digital Eclipse, Nikon, Tokyo, Japan). Microgel suspensions (1-2 mL) were immersed in physiological saline $(10 \mathrm{~mL})$ and vortexed to separate individual beads. Optical images were obtained using a digital camera and further analyzed using the instrument software (EZ CSI version 3.8, Nikon).

\section{Scanning Electronic Microscopy (SEM)}

The bead microstructure was characterized using a benchtop scanning electron microscope (JCM-6000 NeoScope, JEOL, Tokyo, Japan). To prepare the samples prior to analysis, alginate, and chitosan-coated alginate beads were freeze-dried and sputtercoated with gold $(10 \mathrm{~nm})$ before loading onto the microscope. Images of the microgels were documented in representative fields.

\section{Electrical Properties}

The surface potential ( $\zeta$-potential) of alginate and chitosancoated alginate microgels was evaluated by electrophoretic light scattering (Zetasizer Nano ZS, Malvern Instruments, Worcestershire, UK). For each sample, refrigerated microgels (1-2 mL) were suspended in distilled water $(10 \mathrm{~mL})$ and vortexed to separate the beads. Samples were then loaded into the measurement cells and analyzed.

\section{Modeled Long-term Storage Conditions of Encapsulated Bifidobacteria}

Total cell counts of free and encapsulated bifidobacteria were determined by a modified drop plate method as previously described (Herigstad et al., 2001). Briefly, 10 drops $(10 \mu \mathrm{L})$ of a dilution within a series $\left(10^{0}-10^{7}\right)$ were deposited on MRS agar plates and counted after incubation under anaerobic conditions at $37^{\circ} \mathrm{C}$. 
To determine viable counts of the encapsulated bacteria, beads (1 $\mathrm{mL}$ ) were re-suspended in $10 \%$ sodium citrate dihydrate solution $(9 \mathrm{~mL})$ followed by vortexing. The number of released cells was determined by plate count using MRS agar, dilutions of dissolved beads $\left(10^{-1}-10^{-7}\right)$ were plated in duplicate and incubated at $37^{\circ} \mathrm{C}$ anaerobically for $40 \mathrm{~h}$. For lower viability samples later, beads $(2 \mathrm{~mL})$ were re-suspended in $10 \%$ sodium citrate dihydrate solution $(2 \mathrm{~mL})$ instead, and dilutions $\left(10^{0}-\right.$ $10^{-3}$ ) were plated as before. Samples were taken over a 4 -week period on days 0 (initial), 1, 3, 5, 7, 10, 14, 21, and 28. Day 24 was also plated for free cell samples.

\section{In Vitro Simulated Digestion of Alginate and Chitosan-Coated Alginate Microbeads}

Fluids used in in vitro modeling of digestion were prepared based on the method described by Li et al. (2011). One liter of modeled saliva stock solution was prepared with ammonium nitrate $(0.328 \mathrm{~g})$, potassium chloride $(0.202 \mathrm{~g})$, potassium citrate $(0.308 \mathrm{~g})$, potassium phosphate $(0.636 \mathrm{~g})$, sodium chloride (1.594 g), sodium DL-lactate (0.146 g), urea (0.198 g), and uric acid sodium salt $(0.021 \mathrm{~g})$ in distilled water. The stock solution was then filter-sterilized. The day before digestion experiments were carried out, the salivary phase was prepared by adding porcine gastric mucin type II $(2.4 \mathrm{~g})$ to saliva stock solution $(80 \mathrm{~mL})$. The solution was stirred overnight at room temperature to completely dissolve the powder.

One liter of simulated gastric stock solution was prepared by adding sodium chloride $(2 \mathrm{~g})$ and $6 \mathrm{M}$ hydrochloric acid $(7 \mathrm{~mL})$ to distilled water and filter sterilizing. The simulated intestinal stock solution $(500 \mathrm{ml})$ was prepared by adding calcium chloride hexahydrate (27.38 g) and sodium chloride (109.685 g) to distilled water and autoclaved. Pepsin extracted from porcine gastric mucosa $(0.32 \mathrm{~g})$ was then added to gastric stock solution $(100 \mathrm{~mL})$.

The day before digestion experiments were carried out, porcine bile extract $(0.75 \mathrm{~g})$ was added to PBS solution $(14 \mathrm{~mL})$ for the modeled intestinal phase. The solution was stirred overnight at room temperature to completely dissolve the powder. Lipase from porcine pancreas type II $(0.24 \mathrm{~g})$ was dissolved in PBS solution $(10 \mathrm{~mL})$; the solution $(5 \mathrm{~mL})$ was then added with bile salt solution $(7 \mathrm{~mL})$ and intestinal stock solution (33 mL).

Free and encapsulated bifidobacteria cells were separately added to simulated saliva fluids $(22 \mathrm{~mL}, \mathrm{pH}$ adjusted to $6.7-$ 6.8 ), simulated gastric fluids $(45 \mathrm{~mL}, \mathrm{pH}$ adjusted to $2.5-2.6)$ or simulated intestinal fluids ( $45 \mathrm{~mL}, \mathrm{pH}$ adjusted to $7.0-7.2$ ) and stored in a shaking incubator (MaxQ 6000, Thermo Scientific, Waltham, MA, USA) set at $37^{\circ} \mathrm{C}$ with a shaking speed of $110 \mathrm{rpm}$ (Supplementary Figure S1). Dilutions $\left(10^{0}-10^{5}\right)$ were plated on MRS agar for initial, 5, 10, 15, or 30 min exposure and incubated anaerobically for at least $48 \mathrm{~h}$.

\section{Statistical Analysis}

The mean of two or three individual determinations was used to calculate particle size, $\zeta$-potential. The mean of 10 replicate drops was used to calculate cell counts. Analysis of variance (ANOVA) followed by Tukey honest significant difference test was use to analyze all data and compare individual means. This was performed using statistical software (GraphPad Prism 6, GraphPad Software, La Jolla, CA, USA).

\section{RESULTS}

\section{Particle Size Analysis of Alginate and Chitosan-Coated Alginate Microgels}

Light scattering was used to determine the mean particle diameter of the different microgel samples (Table 2). The mean particle sizes of alginate beads containing similar strains were similar, ranging from 135 to $185 \mu \mathrm{m}(\mathrm{D}[3,2])$ for encapsulated $B$. infantis strains and 149-216 $\mu \mathrm{m}$ (D $[3,2])$ for encapsulated B. longum strains. The chitosan-coated alginate beads were significantly larger compared than the alginate beads, ranging from 191 to $292 \mu \mathrm{m}$ (D [3,2]). This increase in particle size may have been because of the additional coating formed by the alginate molecules, or because of some aggregation of the microgels. Microgel aggregation may have occurred due to bridging flocculation, which is the ability of the chitosan cation to adsorb to the surfaces of two or more anionic alginate beads. Additional information regarding the structural configuration of the microgels was therefore obtained through microscopy.

\section{Optical Microscopy of Alginate and Chitosan-Coated Alginate Microbeads}

The structures of samples containing free cells or bacterialloaded microgels were determined using optical microscopy

TABLE 2 | Volume-based (D [4,3]) and surface-based (D [3,2]) mean particle diameters measured by static light scattering alginate and chitosan-coated alginate beads with strains of bifidobacteria.

\begin{tabular}{|c|c|c|c|}
\hline \multirow[t]{2}{*}{ Beads } & & \multicolumn{2}{|c|}{$\mu \mathrm{m}$} \\
\hline & & D $[4,3]$ & D [3,2] \\
\hline \multicolumn{4}{|l|}{ Alg. } \\
\hline \multirow[t]{4}{*}{ Subsp. infantis } & UMA 298 & $233 \pm 4^{\mathrm{ab}}$ & $167 \pm 6^{a b c}$ \\
\hline & UMA 299 & $230 \pm 3^{a b}$ & $162 \pm 3^{b}$ \\
\hline & UMA 300 & $251 \pm 6^{a}$ & $185 \pm 12^{\mathrm{cd}}$ \\
\hline & UMA 305 & $211 \pm 4^{b}$ & $135 \pm 2^{\mathrm{e}}$ \\
\hline \multirow[t]{4}{*}{ Subsp. longum } & UMA 306 & $247 \pm 13^{\mathrm{ac}}$ & $164 \pm 4^{\mathrm{ab}}$ \\
\hline & UMA 318 & $228 \pm 11^{a b}$ & $149 \pm 13^{\text {abe }}$ \\
\hline & UMA 401 & $277 \pm 4^{c d}$ & $216 \pm 3^{f}$ \\
\hline & UMA 402 & $287 \pm 13^{\text {de }}$ & $195 \pm 3^{\text {dfg }}$ \\
\hline \multicolumn{4}{|l|}{ Chit.-alg. } \\
\hline \multirow[t]{2}{*}{ Subsp. infantis } & UMA 299 & $327 \pm 2^{f g}$ & $292 \pm 3^{h}$ \\
\hline & UMA 300 & $344 \pm 14^{f}$ & $237 \pm 3^{i}$ \\
\hline \multirow[t]{2}{*}{ Subsp. longum } & UMA 401 & $310 \pm 20^{e g}$ & $213 \pm 4^{f}$ \\
\hline & UMA 402 & $315 \pm 26^{\text {efg }}$ & $191 \pm 11^{g}$ \\
\hline
\end{tabular}

Values are shown as average particle size \pm standard deviation. Values followed by the same letters in the same column are not significantly different $(p>0.05)$ from each other. 
immediately after encapsulation (Figure 1). Free cells appeared rod-shaped as expected for bifidobacteria (Figures 1A,D). The unfilled alginate and chitosan-coated alginate microgels were similar in morphology, although the individual coated alginate beads did appear larger than the uncoated ones, which is consistent with the particle size analysis (Figures $\mathbf{1 C , F}$ ). Encapsulated bifidobacteria were clearly visualized within the microgels for both alginate and chitosan-coated alginate microgels (Figures 1E,F). The bifidobacterial-loaded alginate and chitosan-coated alginate beads had a similar external appearance as the equivalent unloaded beads. The microgels were generally spherical with diameters around 100-300 $\mu \mathrm{m}$ for all samples.

\section{Scanning Electron Microscopy}

Scanning electron microscopy (SEM) was used to inspect the structure of the alginate and chitosan-coated alginate beads (Figure 2). Freeze-dried microgels were uniform in size and shape. However, the surfaces of the microgels observed by SEM appeared wrinkled, whereas they presented as smooth when observed by optical microscopy. This is likely due to sublimation of water originally trapped within the hydrogel matrix, as has been described previously (Yeung et al., 2016). The chitosancoated alginate beads appeared to be more irregular in shape compared to alginate beads. Qualitatively, the alginate beads had smoother wrinkles and microstructures, whereas the chitosancoated beads exhibited sharp jagged edges. This observation suggests that the chitosan layer has been successfully deposited onto the external surfaces of the alginate microgels.

\section{Zeta Potential Analysis of Microencapsulated Bifidobacteria}

Electrophoretic light scattering was used to evaluate the electrical characteristics of the microgels (Table 3 ). The $\zeta$-potentials of all the alginate beads were negative, ranging from -4.2 to $-9.4 \mathrm{mV}$ for $B$. infantis and -2.6 to $-4.4 \mathrm{mV}$ for $B$. longum as predicted with this coating. In contrast, all chitosan-coated alginate bead samples had positive surface potentials ranging from +9.9 to $+14.9 \mathrm{mV}$ for B. infantis and +0.8 to $+9.0 \mathrm{mV}$ for B. longum. These results indicate that the cationic chitosan molecules formed a secondary shell around the anionic calcium alginate beads.

\section{Survival of Bifidobacterial Strains during Long-term Storage Non-encapsulated Bifidobacterial Cells}

The viability of four B. longum and four B. infantis strains that were not encapsulated was determined during 5 weeks of storage

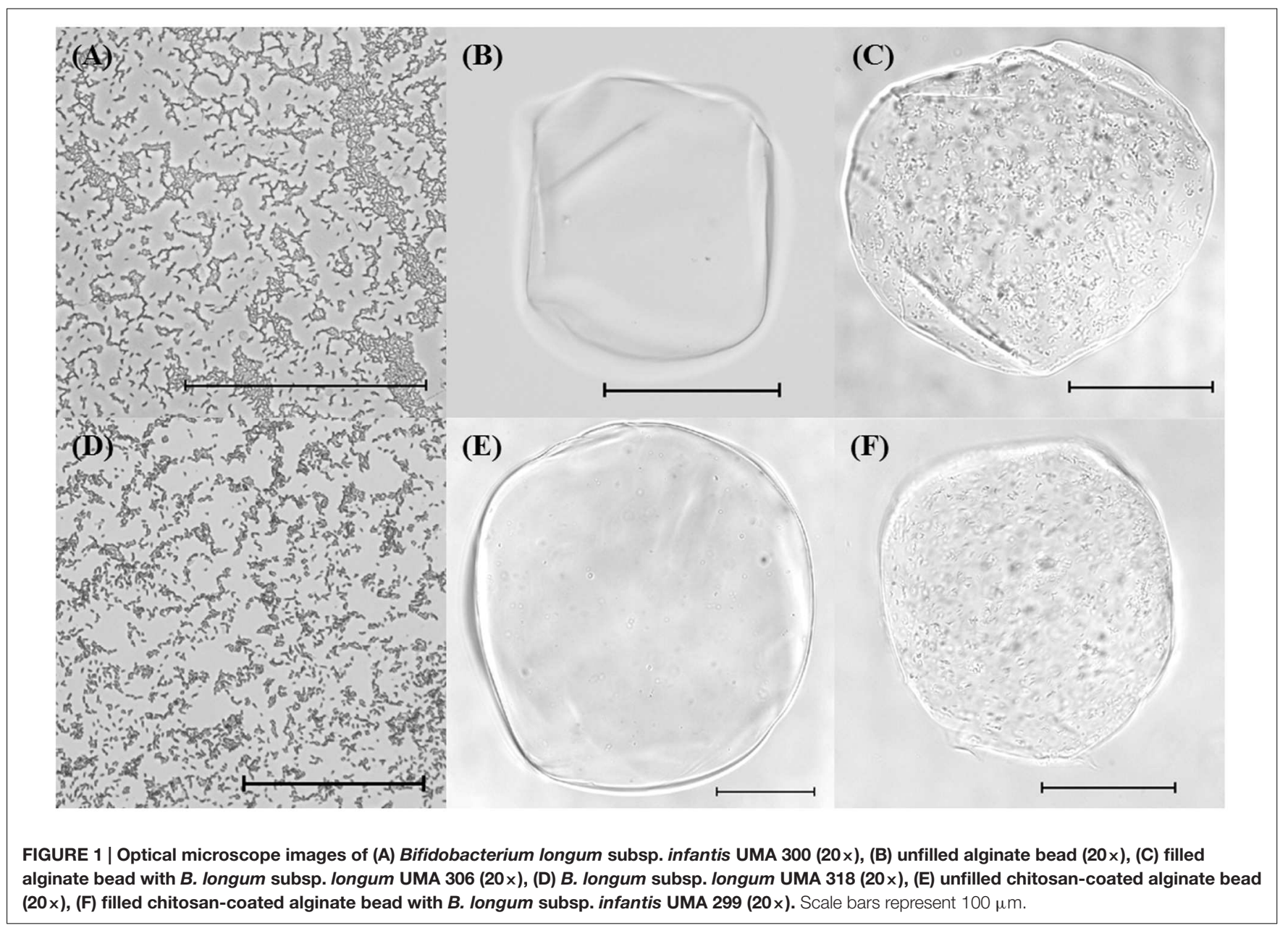



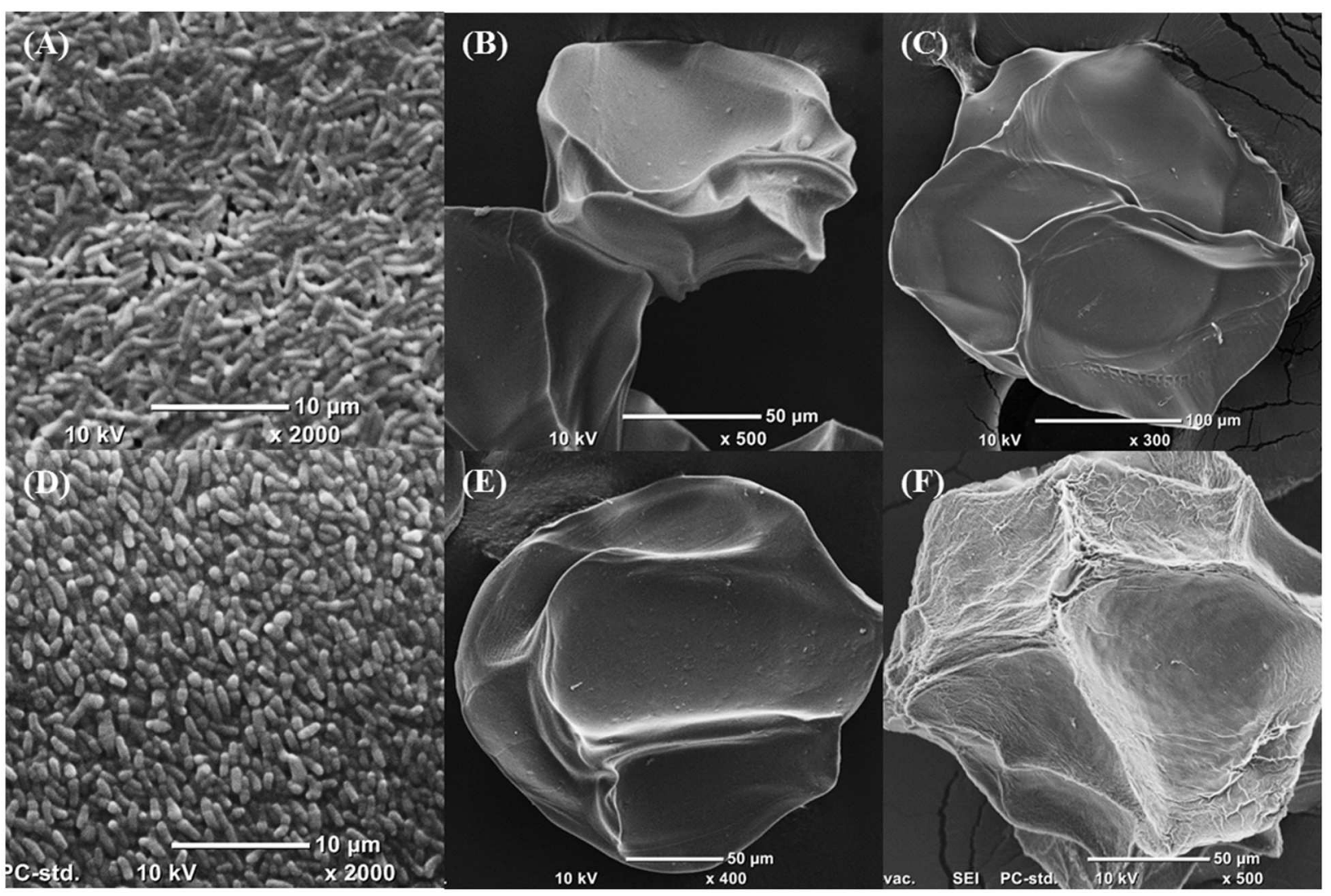

FIGURE 2 | Scanning electron micrographs of (A) B. longum subsp. infantis UMA299, (B) unfilled alginate bead, (C) unfilled chitosan-coated alginate bead, (D) B. longum subsp. longum UMA 306, (E) alginate bead containing B. longum subsp. longum UMA 401, (F) chitosan-coated alginate bead containing B. longum subsp. longum UMA 300. Samples were dried before sputter-coating with gold. SEM was set at high-vacuum, $10 \mathrm{kV}$.

(Figure 3A; Supplementary Table S1). As expected, there was a decrease in the viability of the bifidobacteria evaluated, but the rate of the decrease was strain dependent. A sharp decrease in viability was observed for $B$. infantis UMA318 and B. longum UMA401, diminishing by 9-10 log CFU over the course of a week under aerobic conditions. B. infantis UMA 300 and B. infantis UMA 305 remained viable for slightly longer, with a 10-log reduction observed within 10 days. Whereas, $B$. infantis UMA 298 and $B$. infantis 306 exhibited a 9-10 log decrease over 2 weeks of storage. Interestingly, B. infantis UMA 299 and B. longum UMA 402 survived the longest, as viable cell counts diminished by $7-8$ logs over 3 weeks before decreasing to undetectable levels.

\section{Encapsulated Bifidobacterial Cells}

Viability following encapsulation was determined for all eight bifidobacterial strains (Figure 3B; Supplementary Table S2). There were distinct differences between the effects of encapsulation depending on strain type. The cell viability of B. infantis UMA 298, B. infantis UMA 305, and B. longum UMA 318 stains rapidly decreased and were undetectable after 3 days. Unexpectedly, B. infantis UMA 298 and B. infantis UMA 305 in alginate were inactivated faster than the corresponding free cells,
TABLE 3 | Zeta potential of alginate and chitosan-coated alginate beads with strains of bifidobacteria.

Beads

$\mathrm{mV}$

Alg.

Subsp. infantis

UMA 298
UMA 299
UMA 300
UMA 305
UMA 306
UMA 318
UMA 401
UMA 402

$-5.23 \pm 2.06^{a b}$

$-9.42 \pm 2.54^{a}$

$-8.73 \pm 4.88^{a}$

$-4.15 \pm 1.17^{a b}$

Subsp. longum

$-3.14 \pm 2.24^{\mathrm{ab}}$

$-2.60 \pm 0.04^{a b}$

$-4.38 \pm 0.64^{a b}$

$-4.28 \pm 1.12^{a b}$

Chit.-alg.

Subsp. infantis

UMA 299

$9.92 \pm 3.92^{\mathrm{C}}$

UMA 300

$14.87 \pm 4.26^{c}$

Subsp. longum

UMA 401

$0.79 \pm 2.53^{b c}$

UMA 402

$9.03 \pm 4.90^{\mathrm{cd}}$

Values are shown as average $\zeta$-potential \pm standard deviation. Values followed by the same letters are not significantly different $(p>0.05)$ from each other.

being undetectable after 24 and 10 days, respectively. Viability of the encapsulated B. longum UMA 318 was identical to that of free cells. B. infantis UMA 300, B. longum UMA 306, B. longum 401, 
A

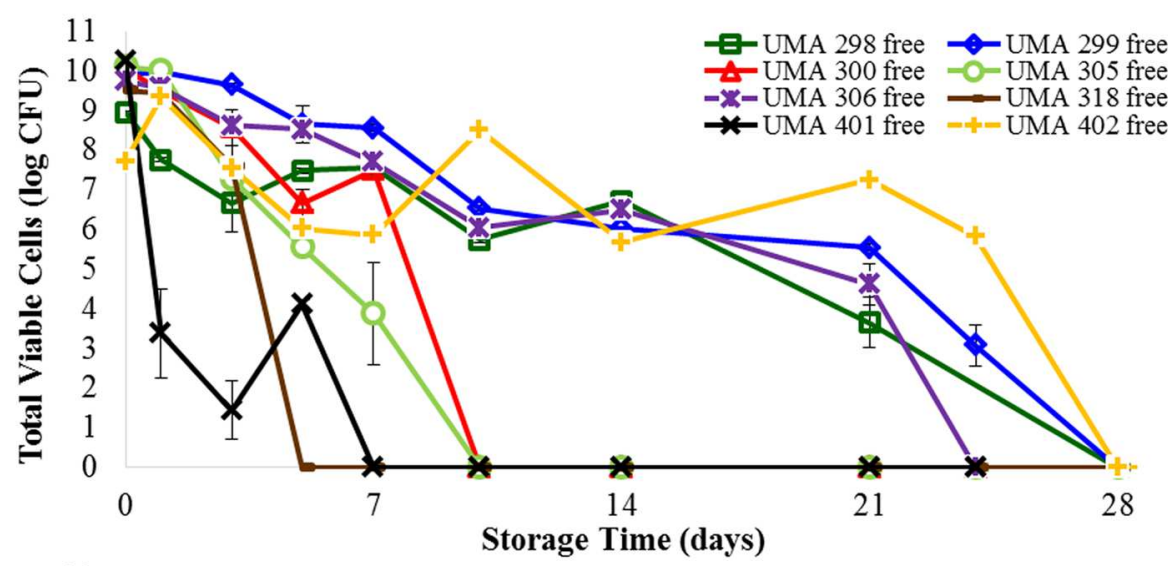

B

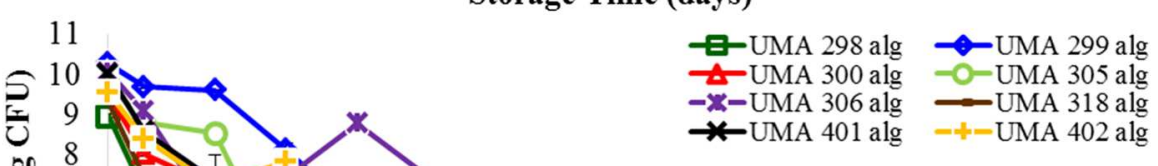

C

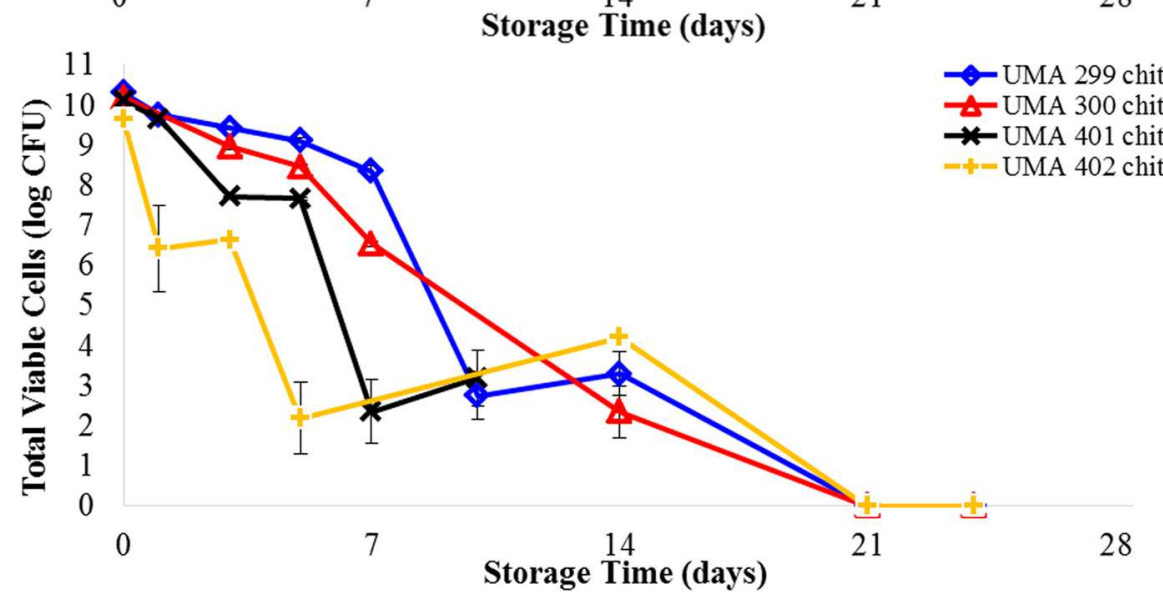

FIGURE 3 | Survival of (A) free B. longum cells, (B) B. longum cells in calcium alginate microbeads, (C) B. longum cells in chitosan-coated alginate microbeads in wet refrigerated storage over time. Counts based on samples drop-plated on MRS agar and incubated at $37^{\circ} \mathrm{C}$ anaerobically. Error bars indicate the standard error of replicate counts $(n=10)$.

and B. longum 402 maintained viable populations that decreased by 3-4 $\log$ CFU after 10 days of storage before rapidly decreasing to zero. Encapsulated B. infantis UMA 300 survived 3 days longer than corresponding free cells; encapsulated B. longum UMA 401 lasted a week longer than free cells. Encapsulated B. longum UMA 306 survived similarly to free cells, and encapsulated B. longum UMA 402 survived over a week shorter than corresponding free cells. Interestingly, B. infantis UMA 299 viability was enhanced as it experienced a $5 \log \mathrm{CFU}$ reduction in 3 weeks compared to an $8 \log$ CFU reduction during this time for the non-encapsulated cells. Thus, encapsulating with alginate extended cell viability of B. infantis UMA 299 and 300 by a few days, and extended viability of $B$. longum UMA 401 cells by a week. Encapsulating other $B$. infantis and B. longum strains 
did not appear to extend viability over the storage conditions used.

Two strains each of $B$. infantis (UMA 299 and 300) and B. longum (UMA 401 and 402) were encapsulated in a secondary coating of chitosan applied to the alginate bead core and submitted to testing over time (Figure 3C; Supplementary Table S3). B. longum UMA 401 and 402 both decreased 3-4 log within 3 days, and fell to undetectable levels by 2 weeks. Viability of B. infantis UMA 299 and B. infantis UMA 300 decreased only 2 logs in 5 days, before falling to undetectable levels after 2 weeks. Encapsulating B. infantis UMA 299, B. infantis UMA 300 , and B. longum UMA 401 cells in chitosan-coated alginate beads did not appear to extend viability compared with uncoated alginate microbeads. B. longum UMA 402 cells in chitosan-coated alginate decreased $2.4 \log \mathrm{CFU}$, whereas B. longum UMA 402 cells in alginate alone decreased $7.2 \log$ CFU, between day 3 and day 14. Hence, encapsulating B. longum UMA 402 in chitosancoated alginate extended detectible viability 4 days more than encapsulating B. longum UMA 402 in alginate alone.

\section{Survival of Encapsulated Cells during Simulated Digestion}

Free and bifidobacterial cells encapsulated in chitosan-coated alginate beads were subjected to simulated digestion in a GIT model as previously described (Li et al., 2011). Free B. infantis UMA 299 and cells encapsulated chitosan-coated alginate were immersed separately in simulated salivary, gastric, and intestinal phases and assessed over time for cell viability (Table 4). The strain was selected based on its high viability during storage in free and encapsulated forms (Table 3; Supplementary Tables S1-S3). The bacteria appeared to be relatively stable within simulated saliva fluids, as less than a $1 \log \mathrm{CFU}$ reduction was experienced in $30 \mathrm{~min}$ of exposure regardless of encapsulation. The model salivary juice did not greatly inhibit cell viability in general, as less than one log CFU reduction was experienced in $30 \mathrm{~min}$ of exposure regardless of encapsulation. However, microencapsulation provided enhanced protection for UMA299 by shielding the strain from the low $\mathrm{pH}$ of the gastric phase. Encapsulated cells decreased by 1.4 logs
CFU, whereas untreated cells decreased by 2.7 logs following exposure to $\mathrm{pH} 2.5$ conditions $(5 \mathrm{~min})$. This indicates a significant, albeit fleeting protection afforded to the encapsulated cells as viability was abrogated after $10 \mathrm{~min}$ of exposure to the gastric phase. Similarly, UMA299 cell viability was not detectible after $5 \mathrm{~min}$ of exposure to the intestinal phase. B. longum UMA 402 encapsulated in chitosan-coated alginate was also subjected to simulated digestion in preliminary tests (data not shown). As with $B$. infantis, cell viability remained stable in the modeled salivary phase, but underwent a 6log reduction after only a few minutes exposure to gastric phase ( $\mathrm{pH} 2.5)$.

\section{DISCUSSION}

Initially, chitosan-coating of alginate beads was postulated to enhance the viability of encapsulated probiotics by reducing their exposure to environmental stresses during storage and within the GIT (Kamalian et al., 2014). Accordingly, the influence of encapsulation on a panel of B. longum strains to assess differential viability was systematically studied. The calcium alginate beads formed using an injection-gelation method were roughly spherical in shape, negatively charged, and had dimensions around 130-220 $\mu \mathrm{m}$. Coating the alginate beads with chitosan caused a small increase in their size and changed their charge from negative to positive. Optical microscopy (Figures 1C,F) confirmed that the bifidobacteria were immobilized within the hydrogel beads, which is consistent with previous encapsulation studies (Hansen et al., 2002; Fareez et al., 2015; Yeung et al., 2016).

Interestingly, encapsulation of bifidobacteria in chitosancoated alginate beads led to decreased improvement in their storage or gastrointestinal stability compared with cells in alginate beads. One possible explanation for this observation is that the alginate hydrogel used had relatively large pores, and so small molecules, such as oxygen, acids, bile salts, or digestive enzymes, could easily diffuse into the microgels and inactivate the encapsulated bacteria (McClements, 2015). These results suggest that a simple secondary layer of chitosan alone

TABLE 4 | Simulated digestion of free and encapsulated B. longum subsp. infantis UMA 299 in three separate stages.

\begin{tabular}{|c|c|c|c|c|c|c|}
\hline \multirow{3}{*}{ Time (minutes) } & \multicolumn{6}{|c|}{$\log$ CFU } \\
\hline & \multicolumn{3}{|c|}{ Free } & \multicolumn{3}{|c|}{ Encapsulated } \\
\hline & Saliva & Gastric & Intestinal & Saliva & Gastric & Intestinal \\
\hline $\mathrm{pH}$ & 6.74 & 2.53 & 7.04 & 6.78 & 2.57 & 7.12 \\
\hline 0 & $9.63 \pm 0.07^{\mathrm{aA}}$ & $9.63 \pm 0.07^{\mathrm{aA}}$ & $9.63 \pm 0.07^{\mathrm{aA}}$ & $8.40 \pm 0.84^{\mathrm{abB}}$ & $8.40 \pm 0.84^{a B}$ & $8.40 \pm 0.84^{\mathrm{aB}}$ \\
\hline 5 & $9.17 \pm 0.06^{a}$ & $6.99 \pm 0.03^{b}$ & ND & $8.10 \pm 0.05^{a}$ & $6.90 \pm 0.04^{a}$ & ND \\
\hline 10 & $9.28 \pm 0.09^{a}$ & ND & ND & $7.89 \pm 0.07^{a}$ & ND & ND \\
\hline 15 & $9.14 \pm 0.06^{a}$ & ND & ND & $6.42 \pm 1.07^{\mathrm{b}}$ & ND & ND \\
\hline 30 & $9.01 \pm 0.06^{a}$ & ND & ND & $8.14 \pm 0.040^{a}$ & ND & ND \\
\hline
\end{tabular}

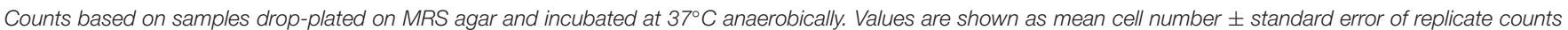

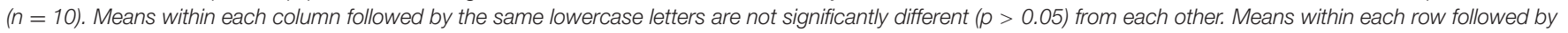
the same uppercase letters are not significantly different $(p>0.05)$ from each other. 
will not fully protect encapsulated bifidobacteria, and that further optimization is required to engineer more effective delivery systems. Previous studies have shown that alginate has a prebiotic effect on bifidobacteria, which might account for its ability to enhanced viability, potentially through a non-encapsulation mechanism (Wang et al., 2006; Ramnani et al., 2012). In future studies, it may be useful to examine the influence of different biopolymer materials and methods on the ability of microgels to enhance probiotic viability. As an example, the hydrogel pore size may be decreased to limit molecular diffusion, with the addition of anti-oxidants to limit oxidation reactions and prebiotics to stimulate probiotic growth in the colon. Since bifidobacteria ferment oligosaccharides within the gut, a synbiotic approach that integrates prebiotic substrates including plant or milk oligosaccharides may advance bifidobacterialbased delivery (Sela, 2011). Alternatively, judicious selection of strain selection that are resistant to acids, bile salts, or digestive enzymes may enhance the delivery scheme. However, previous studies indicate that most bifidobacteria strains typically exhibit a significant decrease in survival around $\mathrm{pH} 4$ which would necessitate shielding from gastric conditions (Sun and Griffiths, 2000).

Bifidobacteria have been exposed to simulated digestive fluids in previously conducted studies (O'Riordan et al., 2001; Hansen et al., 2002; Kamalian et al., 2014). Although specific strains tested and experimental schemes vary between studies. Hansen et al. (2002) encapsulated several bifidobacterial strains in microgels formed by an emulsion-templating method, and then exposed them to simulated gastric and small intestinal fluids. In this study, B. infantis and B. longum strains showed a 4-6 log $\mathrm{CFU} / \mathrm{mL}$ decrease between exposure to gastric fluids set at $\mathrm{pH} 6.0$ and $\mathrm{pH} 2.0$ for $2 \mathrm{~h}$, and 3-5 $\log \mathrm{CFU} / \mathrm{mL}$ reduction between exposure to intestinal fluid containing 0 and $1 \%$ bile for 24 h. Hansen et al. (2002) also encapsulated B. longum experienced a $5-\log \mathrm{CFU} / \mathrm{mL}$ reduction after $30 \mathrm{~min}$ exposure to gastric juice ( $\mathrm{pH} 2.0$ ). In the study herein, B. infantis UMA 299 encapsulated in chitosan-coated alginate underwent an 8$\log$ reduction in a 10-min exposure to gastric fluid ( $\mathrm{pH} 2.6$ ), and an 8 -log reduction in $5 \mathrm{~min}$ exposure to intestinal fluid (Figure 3C; Supplementary Table S3). This study included 0.75\% bile extract, pepsin, and lipases in the gastric and intestinal fluids for the purpose of simulating the harsh conditions of the human GIT. The bifidobacterial general stress response has been studied (Sánchez et al., 2007; Zomer et al., 2009). As with the phylogenetically dissimilar lactic acid bacteria, bifidobacteria employ ATPases to pump protons from the cell when exposed to acidic conditions (Matsumoto et al., 2004; Ventura et al., 2004). In addition, when exposed to bile during gastrointestinal transit, certain bifidobacterial strains deploy bile salt hydrolase to promote cell survival in the small intestine (Ruiz et al., 2014).

In an additional study, an emulsion encapsulation method was performed on B. pseudocatenulatum G4 in chitosan-coated alginate and exposed to gastric conditions ( $\mathrm{pH} 1.5)$ for $2 \mathrm{~h}$ followed by intestinal phase for $5 \mathrm{~h}$ (Kamalian et al., 2014).
The encapsulated B. pseudocatenulatum experienced a 4-log reduction when encapsulated in alginate and a 2-log reduction in chitosan-coated alginate, relative to the 5-log reduction in the control. However, this was accomplished in the absence of digestive enzymes or bile salts in simulated gastric and intestinal fluids that would present additional hurdles to the bifidobacterial cells. O'Riordan et al. (2001) studied spray-dried Bifidobacterium spp. PL1 in starch and subjected the resultant granules to simulated digestion. After $3 \mathrm{~h}$ of exposure to buffer with $\mathrm{pH} 2.8$, they were unable to detect viable cells as well as other sampling points in between 0 and $3 \mathrm{~h}$. This is consistent with the results presented in this study.

In summary, bifidobacterial viability following encapsulation varied between subspecies as well as strains. This suggests that there is a range of genotypic and phenotypic factors contributing to stress responses that promote enhanced viability. Further functional genomic analysis of encapsulated probiotic organisms can aid in matching strains with the particular encapsulation process to optimize cell integrity during storage. Moreover, similar approaches may be used in selecting ideal delivery vehicles to shield bifidobacteria during GIT transit to arrive intact and metabolically poised to exert beneficial activities in the distal colon. Subsequent formulations may optimize delivery vehicles by incorporating antioxidants and cryoprotectants within the encapsulation gel matrix to preserve bifidobacterial cell viability.

\section{AUTHOR CONTRIBUTIONS}

TY, DM, and DS conceived the experimental plan. TY conducted laboratory experiments, data analysis, and drafted the manuscript. EÜ and KT assisted with experiments, analyses, and contributed to the manuscript. DS supervised execution of the experimental plan, analyzed data, and critically reviewed the final manuscript. All authors read and approved the manuscript prior to submission.

\section{ACKNOWLEDGMENTS}

The authors thank TIC Gums for donating sodium alginate for the microencapsulation experiments. We thank David Prodanas for assistance with freeze-drying samples prior to SEM and Ezgi Özcan for assistance with statistical analysis. We also thank Jean Alamed and various individuals at the University of Massachusetts for helpful advice. EÜ thanks the Scientific and Technological Research Council of Turkey (TUBITAK) for financial support under Grant BIDEB 2214/A.

\section{SUPPLEMENTARY MATERIAL}

The Supplementary Material for this article can be found online at: http://journal.frontiersin.org/article/10.3389/fmicb. 2016.00494 


\section{REFERENCES}

Adhikari, K., Mustapha, A., Grün, I. U., and Fernando, L. (2000). Viability of microencapsulated bifidobacteria in set yogurt during refrigerated storage. J. Dairy Sci. 83, 1946-1951. doi: 10.3168/jds.S0022-0302(00)75070-3

Amine, K. M., Champagne, C. P., Raymond, Y., St-Gelais, D., Britten, M., Fustier, P., et al. (2014). Survival of microencapsulated Bifidobacterium longum in cheddar cheese during production and storage. Food Control 37, 193-199. doi: 10.1016/j.foodcont.2013.09.030

Bagchi, D., Lau, F. C., and Ghosh, D. K. (2010). Biotechnology in Functional Foods and Nutraceuticals. Boca Raton, FL: CRC Press.

Braat, H., Rottiers, P., Hommes, D. W., Huyghebaert, N., Remaut, E., Remon, J.-P., et al. (2006). A phase I trial with transgenic bacteria expressing interleukin-10 in Crohn's disease. Clin. Gastroenterol. Hepatol. 4, 754-759. doi: 10.1016/j.cgh.2006.03.028

Capela, P., Hay, T. K. C., and Shah, N. P. (2006). Effect of cryoprotectants, prebiotics and microencapsulation on survival of probiotic organisms in yoghurt and freeze-dried yoghurt. Food Res. Int. 39, 203-211. doi: 10.1016/j.foodres.2005.07.007

Chen, S., Cao, Y., Ferguson, L. R., Shu, Q., and Garg, S. (2013). Evaluation of mucoadhesive coatings of chitosan and thiolated chitosan for the colonic delivery of microencapsulated probiotic bacteria. J. Microencapsul. 30, 103-115. doi: 10.3109/02652048.2012.700959

de Barros, J. M., Lechner, T., Charalampopoulos, D., Khutoryanskiy, V. V., and Edwards, A. D. (2015). Enteric coated spheres produced by extrusion/spheronization provide effective gastric protection and efficient release of live therapeutic bacteria. Int. J. Pharm. 493, 483-494. doi: 10.1016/j.ijpharm.2015.06.051

de Vos, P., Faas, M. M., Spasojevic, M., and Sikkema, J. (2010). Encapsulation for preservation of functionality and targeted delivery of bioactive food components. Int. Dairy J. 20, 292-302. doi: 10.1016/j.idairyj.2009.11.008

Etchepare, M. D. A., Barin, J. S., Cichoski, A. J., Jacob-Lopes, E., Wagner, R., Fries, L. L. M., et al. (2015). Microencapsulation of probiotics using sodium alginate. Ciênc. Rural 45, 1319-1326.

Fareez, I. M., Lim, S. M., Mishra, R. K., and Ramasamy, K. (2015). Chitosan coated alginate-xanthan gum bead enhanced $\mathrm{pH}$ and thermotolerance of Lactobacillus plantarum LAB12. Int. J. Biol. Macromol. 72, 1419-1428. doi: 10.1016/j.ijbiomac.2014.10.054

Fortin, M.-H., Champagne, C., St-Gelais, D., Britten, M., Fustier, P., and Lacroix, M. (2011). Viability of Bifidobacterium longum in cheddar cheese curd during manufacture and storage: effect of microencapsulation and point of inoculation. Dairy Sci. Technol. 91, 599-614. doi: 10.1007/s13594-0110034-5

Gaonkar, A. G., Vasisht, N., Khare, A. R., and Sobel, R. (2014). Microencapsulation in the Food Industry: A Practical Implementation Guide. Amsterdam: Elsevier.

Godward, G., Sultana, K., Kailasapathy, K., Peiris, P., Arumugaswamy, R., and Reynolds, N. (2000). The importance of strain selection on the viavility and survival of probiotic bacteria in dairy foods. Michwissenschaft 55, 441-445.

Gombotz, W. R., and Wee, S. F. (2012). Protein release from alginate matrices. Adv. Drug Deliv. Rev. 64, 194-205. doi: 10.1016/j.addr.2012.09.007

Hansen, L. T., Allan-Wojtas, P., Jin, Y. L., and Paulson, A. T. (2002). Survival of Ca-alginate microencapsulated Bifidobacterium spp. in milk and simulated gastrointestinal conditions. Food Microbiol. 19, 35-45. doi: 10.1006/fmic.2001.0452

Herigstad, B., Hamilton, M., and Heersink, J. (2001). How to optimize the drop plate method for enumerating bacteria. J. Microbiol. Methods 44, 121-129. doi: 10.1016/S0167-7012(00)00241-4

Kamalian, N., Mirhosseini, H., Mustafa, S., and Manap, M. Y. A. (2014). Effect of alginate and chitosan on viability and release behavior of Bifidobacterium pseudocatenulatum G4 in simulated gastrointestinal fluid. Carbohydr. Polym. 111, 700-706. doi: 10.1016/j.carbpol.2014.05.014

Kawasaki, S., Mimura, T., Satoh, T., Takeda, K., and Niimura, Y. (2006). Response of the microaerophilic Bifidobacterium species, B. boum and B. thermophilum, to oxygen. Appl. Environ. Microbiol. 72, 6854-6858. doi: 10.1128/AEM.0121606

Krasaekoopt, W., Bhandari, B., and Deeth, H. (2003). Evaluation of encapsulation techniques of probiotics for yoghurt. Int. Dairy J. 13, 3-13. doi: 10.1016/S09586946(02)00155-3
Krasaekoopt, W., Bhandari, B., and Deeth, H. (2004). The influence of coating materials on some properties of alginate beads and survivability of microencapsulated probiotic bacteria. Int. Dairy J. 14, 737-743. doi: 10.1016/j.idairyj.2004.01.004

Lee, K. Y., and Mooney, D. J. (2012). Alginate: properties and biomedical applications. Prog. Polym. Sci. 37, 106-126. doi: 10.1016/j.progpolymsci.2011.06.003

Lewis, Z. T., Shani, G., Masarweh, C. F., Popovic, M., Frese, S. A., Sela, D. A., et al. (2015). Validating bifidobacterial species and subspecies identity in commercial probiotic products. Pediatr. Res. doi: 10.1038/pr.2015.244 [Epub ahead of print].

Li, Y., Hu, M., and McClements, D. J. (2011). Factors affecting lipase digestibility of emulsified lipids using an in vitro digestion model: proposal for a standardised pH-stat method. Food Chem. 126, 498-505. doi: 10.1016/j.foodchem.2010.11.027

Matsumoto, M., Ohishi, H., and Benno, Y. (2004). H+-ATPase activity in Bifidobacterium with special reference to acid tolerance. Int. J. Food Microbiol. 93, 109-113. doi: 10.1016/j.ijfoodmicro.2003.10.009

McClements, D. J. (2015). Encapsulation, protection, and release of hydrophilic active components: potential and limitations of colloidal delivery systems. $A d v$. Colloid Interface Sci. 219, 27-53. doi: 10.1016/j.cis.2015.02.002

Milani, C., Lugli, G. A., Duranti, S., Turroni, F., Bottacini, F., Mangifesta, M., et al. (2014). Genomic encyclopedia of type strains of the genus Bifidobacterium. Appl. Environ. Microbiol. 80, 6290-6302. doi: 10.1128/AEM.02308-14

Neal-McKinney, J. M., Lu, X., Duong, T., Larson, C. L., Call, D. R., Shah, D. H., et al. (2012). Production of organic acids by probiotic lactobacilli can be used to reduce pathogen load in poultry. PLoS ONE 7:e43928. doi: 10.1371/journal.pone.0043928

O’Riordan, K., Andrews, D., Buckle, K., and Conway, P. (2001). Evaluation of microencapsulation of a Bifidobacterium strain with starch as an approach to prolonging viavility during storage. J. Appl. Microbiol. 91, 1059-1066. doi: 10.1046/j.1365-2672.2001.01472.x

Puccio, G., Cajozzo, C., Meli, F., Rochat, F., Grathwohl, D., and Steenhout, P. (2007). Clinical evaluation of a new starter formula for infants containing live Bifidobacterium longum BL999 and prebiotics. Nutrition 23, 1-8. doi: 10.1016/j.nut.2006.09.007

Ramnani, P., Chitarrari, R., Tuohy, K., Grant, J., Hotchkiss, S., Philp, K., et al. (2012). In vitro fermentation and prebiotic potential of novel low molecular weight polysaccharides derived from agar and alginate seaweeds. Anaerobe 18, 1-6. doi: 10.1016/j.anaerobe.2011.08.003

Roy, D. (2005). Technological aspects related to the use of bifidobacteria in dairy products. Lait 85, 39-56. doi: 10.1051/lait:2004026

Ruiz, L., Gueimonde, M., Ruas-Madiedo, P., Ribbera, A., Clara, G., Ventura, M., et al. (2012). Molecular clues to understand the aerotolerance phenotype of Bifidobacterium animalis subsp. lactis. Appl. Environ. Microbiol. 78, 644-650. doi: 10.1128/AEM.05455-11

Ruiz, L., Margolles, A., and Sánchez, B. (2014). "Bile resistance mechanisms in Lactobacillus and Bifidobacterium," in Microbial Mechanisms of Tolerance to Weak Acids: An Overview, eds N. P. Mira and M. C. Teixeira (Lausanne: Frontiers E-books), 65.

Sakata, S., Kitahara, M., Sakamoto, M., Hayashi, H., Fukuyama, M., and Benno, Y. (2002). Unification of Bifidobacterium infantis and Bifidobacterium suis as Bifidobacterium longum. Int. J. Syst. Evol. Microbiol. 52, 1945-1951. doi: 10.1099/00207713-52-6-1945

Sánchez, B., Champomier-Vergès, M.-C., Stuer-Lauridsen, B., Ruas-Madiedo, P., Anglade, P., Baraige, F., et al. (2007). Adaptation and response of Bifidobacterium animalis subsp. lactis to bile: a proteomic and physiological approach. Appl. Environ. Microbiol. 73, 6757-6767. doi: 10.1128/AEM.00637-07 Schell, M. A., Karmirantzou, M., Snel, B., Vilanova, D., Berger, B., Pessi, G., et al. (2002). The genome sequence of Bifidobacterium longum reflects its adaptation to the human gastrointestinal tract. Proc. Natl. Acad. Sci. U.S.A. 99, 14422-14427. doi: 10.1073/pnas.212527599

Seiffert, S. (2013). Microgel capsules tailored by droplet-based microfluidics. ChemPhysChem 14, 295-304. doi: 10.1002/cphc.201200749

Sela, D., Chapman, J., Adeuya, A., Kim, J., Chen, F., Whitehead, T., et al. (2008). The genome sequence of Bifidobacterium longum subsp. infantis reveals adaptations for milk utilization within the infant microbiome. Proc. Natl. Acad. Sci. U.S.A. 105, 18964-18969. doi: 10.1073/pnas.0809584105 
Sela, D. A. (2011). "Bifidobacterial utilization of human milk oligosaccharides," in Proceedings of the 3rd International Symposium on Propionibacteria and Bifidobacteria: Dairy and Probiotic applications, 1-4 June 2010, Vol. 149, Oviedo, 58-64.

Sela, D. A., and Mills, D. A. (2010). Nursing our microbiota: molecular linkages between bifidobacteria and milk oligosaccharides. Trends Microbiol. 18, 298-307. doi: 10.1016/j.tim.2010.03.008

Sultana, K., Godward, G., Reynolds, N., Arumugaswamy, R., Peiris, P., and Kailasapathy, K. (2000). Encapsulation of probiotic bacteria with alginatestarch and evaluation of survival in simulated gastrointestinal conditions and in yoghurt. Int. J. Food Microbiol. 62, 47-55. doi: 10.1016/S0168-1605(00) 00380-9

Sun, W., and Griffiths, M. W. (2000). Survival of bifidobacteria in yogurt and simulated gastric juice following immobilization in gellan-xanthan beads. Int J. Food Microbiol. 61, 17-25. doi: 10.1016/S0168-1605(00)00327-5

Sun, Z., Zhang, W., Guo, C., Yang, X., Liu, W., Wu, Y., et al. (2015). Comparative genomic analysis of 45 type strains of the genus Bifidobacterium: a snapshot of its genetic diversity and evolution. PLoS ONE 10:e0117912. doi: 10.1371/journal.pone.0117912

Ventura, M., Canchaya, C., van Sinderen, D., Fitzgerald, G. F., and Zink, R. (2004). Bifidobacterium lactis DSM 10140: identification of the atp (atpBEFHAGDC) operon and analysis of its genetic structure, characteristics, and phylogeny. Appl. Environ. Microbiol. 70, 3110-3121. doi: 10.1128/AEM.70.5.31103121.2004

Wang, Y., Han, F., Hu, B., Li, J., and Yu, W. (2006). In vivo prebiotic properties of alginate oligosaccharides prepared through enzymatic hydrolysis of alginate. Nutr. Res. 26, 597-603. doi: 10.1016/j.nutres.2006.09.015

Watson, R. R., and Preedy, V. R. (2015). Probiotics, Prebiotics, and Synbiotics: Bioactive Foods in Health Promotion. Boston, MA: Academic Press.

Whelehan, M., and Marison, I. W. (2011). Microencapsulation using vibrating technology. J. Microencapsul. 28, 669-688. doi: 10.3109/02652048.2011.586068
Yeung, T. W., Arroyo-Maya, I. J., McClements, D. J., and Sela, D. A. (2016). Microencapsulation of probiotics in hydrogel particles: enhancing Lactococcus lactis subsp. cremoris LM0230 viability using calcium alginate beads. Food Funct. doi: 10.1039/C5FO00801H [Epub ahead of print].

Zhang, Z., Zhang, R., Chen, L., Tong, Q., and McClements, D. J. (2015a). Designing hydrogel particles for controlled or targeted release of lipophilic bioactive agents in the gastrointestinal tract. Eur. Polym. J. 72, 698-716. doi: 10.1016/j.eurpolymj.2015.01.013

Zhang, Z., Zhang, R., Decker, E. A., and McClements, D. J. (2015b). Development of food-grade filled hydrogels for oral delivery of lipophilic active ingredients: pH-triggered release. Food Hydrocoll. 44, 345-352. doi: 10.1016/j.foodhyd.2014.10.002

Zhou, Y., Martins, E., Groboillot, A., Champagne, C., and Neufeld, R. (1998). Spectrophotometric quantification of lactic bacteria in alginate and control of cell release with chitosan coating. J. Appl. Microbiol. 84, 342-348. doi: 10.1046/j.1365-2672.1998.00348.x

Zomer, A., Fernandez, M., Kearney, B., Fitzgerald, G. F., Ventura, M., and van Sinderen, D. (2009). An interactive regulatory network controls stress response in Bifidobacterium breve UCC2003. J. Bacteriol. 191, 7039-7049. doi: 10.1128/JB.00897-09

Conflict of Interest Statement: The authors declare that the research was conducted in the absence of any commercial or financial relationships that could be construed as a potential conflict of interest.

Copyright (c) 2016 Yeung, Üçok, Tiani, McClements and Sela. This is an open-access article distributed under the terms of the Creative Commons Attribution License (CC BY). The use, distribution or reproduction in other forums is permitted, provided the original author(s) or licensor are credited and that the original publication in this journal is cited, in accordance with accepted academic practice. No use, distribution or reproduction is permitted which does not comply with these terms. 